\title{
An Independent Review of Several Successful Hospital Incident Command System (HICS) Implementations and Lessons Learned
}

\author{
Julie Bulson ${ }^{1 *}$ and Tim Bulson ${ }^{2}$ \\ ${ }^{1}$ Director, Emergency Preparedness, USA \\ ${ }^{2}$ Director, Community Relations, , USA
}

*Corresponding author: Julie Bulson, Director, Emergency Preparedness, Spectrum Health, USA

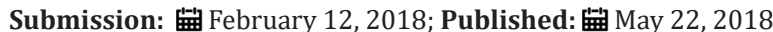

\begin{abstract}
US hospitals are required by Joint Commission to utilize a command structure that is compliant with the National Incident Management System (NIMS). Most utilized is the Hospital Incident Command System (HICS) which guides any disaster response. Further, hospitals are required to NIMS guidelines when responding to events that predicate the implementation of disaster plans or protocols - especially when hospital leaders will interact with local, state or federal authorities. These mandates have grown in depth and breadth since all first responder disciplines began to update their local policies, procedures, and education requirements in the post-9/11 preparedness environment.

This new environment includes ongoing federal grants designed to increase hospital preparedness and capacity, but with the fund are mandates requiring hospitals to educate staff members in NIMS education and its use. As a result, many hospitals have adopted HICS and NIMS as the general frameworks on which they build disaster plans, education sessions, and disaster drills. While federal and state officials continue to track compliance with federal requirements, there seems to be a gap in tracking use and effectiveness of HICS and NIMS in real-life incidents, whether planned or emergent. This article examines the real-life experiences of one 1,000+ bed Michigan hospital system that used HICS and NIMS during responses to a state funeral, a credible bomb threat, and a helicopter crash.
\end{abstract}

\section{Introduction}

As medical care and public health providers reflect on the start of the $21^{\text {st }}$ century, they will consider a range of events that influenced their priorities, from post-hurricane relief to fear of terror attacks to the first declared avian flu pandemic since 1968, when H3N2 reportedly killed 700,000 people [1].

While United States hospitals have always had disaster plans in place, the terrorist acts of September 11th, Hurricane Katrina, and the threat of emerging infectious diseases have increased our assessment of the likelihood of disaster and raised the bar for preparedness [2]. Among the organizations directly affected by these events and subsequent calls for enhanced disaster preparedness are the 2,849 non-government, not for profit community hospitals [3] - of which the Michigan healthcare system is one.

Though the hospital physicians and staff plan for disasters much like their peers, they have learned significant lessons from unique real-life experiences that include response to a presidential funeral, a credible bomb threat to one of its hospitals, and a medical helicopter rooftop crash.

\section{Background}

The incidents to be reviewed occurred at the main hospital of a large Midwest healthcare system within the United States. The system is comprised of several rural and urban acute and long term care facilities which include a level 1 adult and pediatric center along with the regional burn center.

This system, like many other healthcare organizations, has adopted the Hospital Incident Command System (HICS) and the National Incident Management System (NIMS) as its models for disaster response, in part to meet requirements of The Joint Commission (Assistant Secretary for Preparedness and Response, 2015; “Emergency Management | Joint Commission," nd). HICS began in the late 1980 s as the Hospital Emergency Incident Command System (HEICS) and evolved to HICS, which is "a comprehensive incident management system intended for use in both emergent and non-emergent situations" [4]. Also important to note, this system has also worked closely since 2002 with local, regional and state preparedness partners active in federal Hospital Preparedness Program (HPP) efforts across Michigan [5]. 
This healthcare system is not unique, as hospitals spend a great deal of time and resources on preparation activities including developing, testing, and refining disaster response logistics and clinical plans for various simulated events [2]. Nor is this new to the industry, as healthcare systems have long been required to perform disaster drills to assess their readiness in the event of a real disaster [6-8]

As a requirement for accreditation, hospitals complete an annual Hazard Vulnerability Assessment (HVA) and update education and exercise opportunities for management / staff based on the results of the HVA. There is also the opportunity for management staff that respond to the hospital command center (HCC) to complete the required and suggested NIMS and Incident Command System (ICS) courses and to participate in drills or exercises [7-9].

The impetus for community hospitals (and others) to use NIMS and ICS comes in part from The Joint Commission and the Center for Medicaid and Medicare Services (CMS), which accredits many healthcare organizations and provides the standards hospitals must meet [6,8]. Included is Standard 01.01.01, which calls for a hospital incident command structure to be integrated into [10].

This article will review three hospital command center responses to a planned event and two unplanned incidents that occurred at local community hospitals. The documentation of the significant lessons learned is critical within the healthcare emergency preparedness environment to ensure a strengthened response.

\section{State Funeral}

The interment of President Gerald R. Ford occurred shortly after U.S. hospitals moved from HEICS to the HICS model and allowed this healthcare system to test its proficiency with the new model during a planned event. Communities with ties to high profile persons (e.g. elected officials, entertainers, philanthropists or athletes) and those that host large events (e.g. the National Football League Super Bowl) may condition themselves to be ready for unexpected turns in even the most well-planned of events.

The Joint Commission provides guidance and standards relative to the use of a hospital command center (HCC) to manage hospital response and community roles in such events [10]. Other agencies echo this suggestion. There are non-emergent situations in which activation of the HCC and use of the Hospital Incident Command System is valuable. Examples of such situations include moving patients into a new part of the facility, weather-related emergencies such as snow storms, or mass gathering events being held in the community. The HICS should be developed to the extent necessary to manage the anticipated situations that could occur [4].

It is this strategy that worked to this healthcare system's advantage as emergency planners determined the Ford interment was an opportunity to test new HICS guidelines. Hospital officials began in 2007 preparing for contingencies related to the state funeral in the adopted hometown of the 38th U.S. President, who died December 26, 2006 in Rancho Mirage, California.
Longstanding plans called for the president to be buried on the grounds of the Gerald R. Ford Museum and Presidential Library, formally dedicated in downtown Grand Rapids in April 1981 and opened to the public that September. After ceremonies in California, Washington, and Grand Rapids, he was interred on the grounds of the Ford Museum. Funeral services for President Ford were held at St. Margaret's Parish in Palm Desert, California; at the U.S. Capitol Rotunda and the National Cathedral in Washington, D.C.; and at Grace Episcopal Church in Grand Rapids, Michigan [11]. A formal procession marked the journey of President Ford from Grace Episcopal Church to the burial site at the Museum in downtime Grand Rapids, MI - approximately six miles apart.

As plans for President Ford's interment were announced, the main campus of this Midwest healthcare system emergency preparedness staff and the hospital disaster committee discussed the potential for road closings to hinder Emergency Medical Services (EMS) routes to the hospital Emergency Department, a verified Level I Trauma Center; and into another community hospital, at that time the only burn center in the region. The presidential museum is several blocks from the trauma center, and the church that housed religious services is less than one mile from the burn center. Hospital planners were also proactive in planning for sudden illness or injury to a visiting dignitary, or the chance of a mass casualty incident [12]

What is the primary lesson other hospital, EMS, and community emergency planners may take from this event? Expect more than is planned. For instance, statistics show more people paid respects to President Ford in Grand Rapids than in Washington, D.C [11]:

A. An estimated 36,000 visited the US Capital Rotunda as President Ford lay in State.

B. As President Ford lay in repose at the Museum, Tuesday afternoon through Wednesday morning, some 62,000 people paid their respects, including the estimated 57,000 people who entered the queue through DeVos Place and waited patiently in line.

C. In addition, an estimated 75,000 people lined the streets of Grand Rapids to welcome President Ford home on January 2, 2007 and during the funeral services on January 3, 2007.

Events did not directly affect the system's community hospital until a last-minute change in the route from the airport to the church for Vice President Richard Cheney's motorcade blocked roads around the emergency department. Among closed roads were main arteries used for routine deliveries and patient / family access for discharges and surgeries, as well as by hospital staff coming and going for an early afternoon shift change.

As noted, the hospital had already decided to partially staff its HCC on January 3 for the duration of the church service, processions and interment. The HCC positions staffed were comprised of: an Incident Commander; Liaison Officer; and, a Safety/Security Officer. Predetermined incident action plan goals included: 
A. A test of redundant radio communications with local partners;

B. Use of a regional, HPP funded, web-based bed tracking system (EM System);

C. Use of an emergency management event tracking system (E-Team);

D. Monitor events and discuss potential for worst-case scenarios as they unfolded;

E. Determine potential scope of impact of emergency department / EMS routes;

F. Monitor activity for the potential to divert patients from the in-house burn center; and

G. Determine whether any additional communications links to other agencies or hospitals were needed [13].

As soon as modifications on the road closures were given to HCC staff, that team discussed the impact with EMS agencies and determined the most prudent decision was to close the hospital emergency department to EMS traffic. While the closures were more problematic than critical, HCC staff took this opportunity to post hospital information on E-Team (the state emergency operations center documentation tool) and to discuss potential for further road closures with the local Emergency Operations Center (EOC) Similarly, the hospital posted notes of road closures on EM System, and used new equipment and software to generate area road maps with highlighted closures that were then saved in a PDF format and posted on the hospital intranet and sent to departments via e-mail.

Though events were not long or significant enough to affect hospital operations, the two hour HCC test demonstrated significant lessons:

A. Staff trained in HCC and ICS procedures worked well together as circumstances changed;

B. Details will change, even in events that were pre-planned down to the minute;

C. Pre-established communications links allowed partners - from healthcare and from emergency management care - to share vital information immediately;

D. Pre-established events on systems like E-Team and EM System allowed the primary hospital and community partners to share real-time data without having to complete set-up or notification steps as events unfolded; and,

E. Technology tests allow HCC staff to become familiar with tools they will need on the fly.

The healthcare system leaders suggest these lessons demonstrate practical applications of one of the "NIMS Implementation Objectives for Healthcare Organizations" set by the Department of Homeland Security via the Federal Emergency Management Agency (FEMA) for fiscal 2015. In particular, objective
8 calls for systems, tools and processes that "facilitates the collection and distribution of consistent and accurate information during an incident or event" [8]. The affected command staff who used the described systems in this event suggest response tools like these can be effectively applied by partners in other communities working through pre-planned events, no matter how large or small the community or the event. Despite extensive pre-planning, "no one can predict when events will occur; therefore, healthcare organizations must be in a constant state of readiness to respond to threats and be prepared to provide quality patient care during any disaster" [14].

\section{Bomb Threat}

That's the position the healthcare system community hospital found itself in on March 28, 2008. A HCC response began about 10AM. That Saturday, shortly after staff members at two local community hospitals and a television station 55 miles away shared details with each other surrounding a telephone caller who allegedly openly discussed threats against the healthcare system specifically their local community hospital.

As soon as the agencies involved notified local police of the threat, officers immediately responded to the local hospital. Based on threat details and known history of the suspected caller, the hospital Security Police called for an internal bomb threat response plan, which included an immediate search by hospital staff for any obvious, out of place, unusual packages. Shortly thereafter, local police deemed the threat credible enough to warrant a thorough search of the entire hospital by officers with bomb sniffing dogs from one of the local police departments and the Michigan State Police.

Within one hour of the threatening calls, a partial hospital command center was established in a room near the campus security office. Staff included the hospital preparedness manager, on-call executive administrator, hospital security leadership, patient relations executive, the in-house nursing supervisor, and because of participation in Michigan's regionalized hospital preparedness efforts, the regional preparedness staff member responded as a liaison with state and federal officials.

Staff filled HCC positions comprised of: the Incident Commander; Safety / Security Officer; Liaison Officer; and, the Public Information Officer. Overarching incident action plan goals included the need to close the hospital emergency department to all ambulance traffic and to:

A. Open communications with local police to share consistent and reliable information;

B. Determine a need to lock down the facility and cancel elective procedures;

C. Provide appropriate liaisons to police search teams, including floor plans and similar information;

D. Monitor situation/discuss potential for worst-case scenarios; 
E. Determine potential scope of impact of emergency department;

F. Monitor activity for the potential to divert patients from the in-house burn center;

G. Determine whether any additional communications links to other agencies or hospitals were needed;

H. Provide information to Michigan Department of Community Health Office of Public Health Preparedness for potential Health Alert Network (HAN) information on diversions, and to open communications with the regional Department of Homeland Security staff member; and,

I. Monitor media coverage and update on-campus reporters.

Bomb search teams scoured the hospital proper, some 505,802 square feet, over five hours. By late afternoon, police and hospital officials determined there was no device on the campus, though several law enforcement agencies continued an intense search for the suspect. He was later arrested and described in the local media as "a Grand Rapids-area man in custody (that) Saturday and faces arraignment for a bomb threat at [a local hospital]. The hospital was sealed off for five hours following a threat that was phoned into WWMT-TV and [another local hospital] about noon" ("Blodgett Hospital bomb threat suspect arrested after giving partial name MLive.com," 2008).

Beyond the practical advantage of hospital and police or emergency management staff knowing each other and understanding expected roles during a crisis, nurturing these partnerships also supports NIMS Implementation Objective language that says "The implementation of these objectives enhances the relationship between healthcare organizations and their respective local government, public health and other emergency response agencies" [8]. This healthcare system emergency preparedness team suggests a credible threat is not the time for introductions; it is a time for prompt action based on trust and respect generated over time.

Perhaps the most important lesson learned from this incident is that hospitals and other health care organizations must continue to strengthen communications and partnerships with local, regional and state law enforcement agencies and others vital to a response. Further, the system emergency preparedness staff would suggest these links are even more vital when a hospital or healthcare entity becomes a crime scene or site where victims are injured (e.g. a fire, flood or tornado damaging the facility) - or the site of a helicopter crash.

\section{Helicopter Crash}

Events began at 11:01AM on May 29, 2008 when, during a planned air medical test flight, the aircraft crashed onto the helistop atop the 11-story hospital building. Among those to sound the first alarms, including a fire-alarm pull station, were Facilities Support staff members on a mechanical floor below the helistop. Responding local fire units deployed to the rooftop on the building's 11th floor reached the helistop in minutes, as local police units closed all roads and established a secure perimeter around the entire campus. Published accounts confirmed the pilot and a Federal Aviation Administration (FAA) official escaped from the helicopter on their own to a safer area of the roof where they were rescued by several fire fighters, while others began fire suppression efforts [15].

The HCC was established about 11:17AM Fire command was opened at the main Emergency Department entrance. Shortly thereafter, fire and police established a Unified Command site near the Emergency Department. The HCC was open from 11AM9PM on May 29 to manage the immediate incident; it re-opened during business hours on May 30 to monitor and support recovery; and opened again from 9:30AM - 3PM on June 1; this last day to support the movement of pediatric patients back to two floors of the Children's Hospital.

Even though the HCC scaled back its hours after May 30, trained command staff maintained a schedule of daily command meetings for several days to focus on priorities that included:

A. Patients: Maintain safety and full range of patient care for the entire campus and particularly on temporary patient care units;

B. Utility status: A return to normal power from parts of the campus that went on generator power to maintain critical systems that lost power due to the fire;

C. Air: Monitor air temperature, quality, and movement and ensure return to normal air flow systems;

D. General communications: Provide scheduled internal and external communications updates; and,

E. Structural integrity: To monitor progress of engineering updates relative to roof integrity and implement final stages of facility clean-up.

As part of its normal procedures after the implementation of any hospital disaster plan, a debriefing was held that included dozens of departments and key community representatives (e.g. local Police and Fire Department) to develop an opportunities list. Key areas for improvement that need resolution are documented on an improvement matrix, and by policy are reviewed by representatives of the hospital disaster committee or appropriate department representatives, committees or others for final disposition [16]

As noted earlier, hospitals should foster open communications with partner agencies. Among the key lessons others can learn from this incident is how immediate and valuable partner response can be if, or when, a hospital becomes a disaster scene. In this case, staff has worked diligently for more than 16 years with more than 20 other hospitals in one of Michigan's HPP regional planning coalitions. On May 29, members of this HPP coalition (including health care and non health care partners), the Michigan Department 
of Community Health, Department of Homeland Security and the local EMS regulatory agency all responded in person, via electronic notification systems or by region-wide radio communications.

The hospital and these partners used HICS and NIMS as the roadmap to response. The HCC used all command and general staff positions to ensure all above-mentioned priorities were met for three consecutive days, while collaborating with the local and regional response partners. The ICS structure allowed fire, police, and hospital leaders to establish a command and control system that ensured patient safety, a safe rescue by fire fighters, safe and effective fire suppression, a secure perimeter around the entire hospital campus, and a return to normal operations for the vast majority of the campus just several hours after the incident began.

Beyond strong partnerships and open interdisciplinary communications, the emergency preparedness team suggests hospitals and health care systems use the readily available tools to enhance or standardize their preparedness planning.

\section{Summary}

While these examples demonstrate success of the incident command system at a large healthcare system's local community hospitals, this success would not have been possible without significant education and the support of the leadership team. Further leadership command center training was identified as a follow up item. As a result, a solid leadership incident command system education program has been developed for all leaders managers through executive leadership levels.

Table 1: Hospital command center education survey results.

\begin{tabular}{|c|c|c|}
\hline Question & Before Education & After Education \\
\hline I feel efficient in my role in the & YES-25\% & YES-98\% \\
\cline { 2 - 3 } HCC & NO-57.7\% & NO-0\% \\
\hline $\begin{array}{c}\text { I am efficient in eICS } \\
\text { documentation }\end{array}$ & YES-9.62\% & YES-98\% \\
\cline { 2 - 3 } & NO-80.7\% & NO-0 $\%$ \\
\hline $\begin{array}{c}\text { The command center } \\
\text { exercise helped me to better } \\
\text { understand HCC functionality }\end{array}$ & N/A & YES-100\% \\
\hline $\begin{array}{c}\text { I would recommend this } \\
\text { training to everyone who holds } \\
\text { a position in the HCC }\end{array}$ & N/A & YES-100\% \\
\cline { 3 - 3 } & & NO-0\% \\
\hline
\end{tabular}

Currently, all leaders prior to being on call for the organization must go through an incident command class outlining the HICS system and the use of electronic documentation tools. This education outlines the various HCC roles and responsibilities, reviews the federal incident management plan, and the integration into the local, regional, and state response programs. This education is offered quarterly system wide to ensure compliance with all participants completing surveys after every class. The results of those surveys support the need and the benefit of this education (Table 1).

It is critical to follow up an incident or plan implementation with a debriefing of lessons learned to ensure improvements are identified and processes are updated. This education program has been invaluable to Spectrum Health and the success of command center responses. In the end, what is most important is the drive to capture and share what is learned. In a 1996 editorial in The Journal of Emergency Medicine, Jacoby reminded us all that "History repeats itself and teaches us. We should take heed and learn its lessons" [16,17].

\section{References}

1. (2018) Timelines, Avian Flu.

2. American Hospital Association (2015) Always there, ready to care: The 24/7 role of America's hospitals. American Hospital Association, Chicago, USA, pp. 1-20.

3. Health Forum LLC (2018) Fast Facts on US hospitals (AHA Hospital Statistics). American Hospital Association, Chicago, USA.

4. California Emergency Medical Services Authority (2014) HICS Guidebook ( $5^{\text {th }}$ edn), EMSA, USA.

5. US Department of Health \& Human Services (2014) Hospital preparedness program overview - PHE, USA.

6. Center for Medicaid and Medicare Services (2018) Emergency-preprule.

7. Drenkard K, Rigotti G, Hanfling D, Fahlgren T, La Francois G (2002) Healthcare system disaster preparedness, part 1: Readiness planning. The Journal of Nursing Administration 32(9): 461-469.

8. Assistant Secretary for Preparedness and Response (2015) NIMS implementation for healthcare organizations guidance. Hospital Preparedness Program, USA.

9. (2008) Blodgett hospital bomb threat suspect arrested after giving partial name.

10. Emergency Management (2018) Joint Commission.

11. Gerald R (2018) Ford Presidential Library and Museum.

12. Bulson JA, Mattice C, Bulson TC (2012) A systematic approach to very important person preparedness for a trauma center. Journal of Trauma Nursing 19(1): 11-14.

13. Intermedix (2018) Patient Tracking, EM Track, Intermedix.

14. Fahlgren T, Drenkard K (2002) Healthcare system disaster preparedness, part 2: Nursing executive role in leadership. The Journal of Nursing Administration 32(10): 531-537.

15. Estep D (2008) Helicopter crash at butterworth hospital: Firefighters reached roof "just in time."

16. Jacoby I (1996) Lessons for hospitals from the midwest flood of 1993. The Journal of Emergency Medicine 14(3): 379-380.

17. NC4 (2018) E Team: Public Safety and Incident Management Solutions, USA. 
Creative Commons Attribution 4.0 International License

For possible submissions Click Here

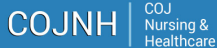

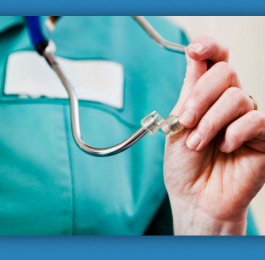

\section{COJ Nursing \& Healthcare}

Benefits of Publishing with us

- High-level peer review and editorial services

- Freely accessible online immediately upon publication

- Authors retain the copyright to their work

- Licensing it under a Creative Commons license

- Visibility through different online platforms 